\title{
Pregnancy and congenital heart disease
}

Congenital heart disease is now more common in pregnancy because of the major improvements in the survival of children with congenital heart disease. At the same time paediatric and adult cardiology have become more separated and adult cardiologists have often had inadequate exposure to congenital heart disease during their training. Pregnant women prefer local care and experience is diluted. The literature is anecdotal.

Patients who have had holes closed or valves opened may have moved to a different part of the country and been lost to follow up. They may be left with residual or progressive disease but think they are cured. Children surviving into the reproductive age after heroic but palliative surgery in infancy may be left with complex abnormalities, however, all of them want to lead normal adult lives with jobs, cars, and families. They want to have children.

Complete diagnosis and an assessment of cardiovascular reserve are basic. Most patients who were allegedly asymptomatic or barely symptomatic before pregnancy will be fine, but there are exceptions. Safety and success depend on the ability to raise stroke volume or to tolerate a reflex rise in heart rate. Because of lowered systemic vascular resistance, cyanosed or potentially cyanosed patients with a fixed obstruction to flow to or within the lungs will increase right to left shunting during pregnancy. Patients with congenital heart disease are not immune from superimposed pre-eclampsia or peripartum cardiomyopathy.

Women at particular risk are those with:

- left sided obstructive lesions

- pulmonary hypertension

- poor ventricular function

- potentially fragile aortas

- valve prostheses

- cyanosis.

Congenital defects are quite frequently initially detected in the antenatal clinic when a murmur, perhaps heard for the first time because of the increased cardiac output, prompts echocardiography. Most common are atrial septal defects but restrictive ventricular septal defects and arterial ducts, pulmonary stenosis, and acyanotic Ebstein's anomaly are also found.

Even major abnormalities are sometimes first diagnosed during pregnancy. Corrected transposition without other substantive defects may be noticed because of a pansystolic murmur caused by a regurgitant left sided tricuspid valve-a loud "P2" from the anteriorly placed left sided aortic valve suggesting pulmonary hypertension or atrioventricular block. Most do well. New immigrant wives from unmonitored communities may present with a variety of disorders including the Eisenmenger syndrome.

Patients with previously corrected septal defects do well unless there is residual pulmonary hypertension. Pulmonary or aortic stenosis may have been treated by the interventional cardiologist or by valvotomy in earlier years, but aortic valve stenosis in particular tends to increase in severity with growth and the passage of time and, unlike pulmonary stenosis, may not be well tolerated in pregnancy.
Complex defects previously palliated include single ventricles or transposition with pulmonary stenosis or atresia that have been shunted, Fontan circulations, Rastelli valve bearing conduits or interatrial and arterial switches for transposition.

\section{Atrial septal defect}

The only frailty of patients with a repaired atrial septal defect is intolerance of blood loss that can force left to right shunting, to the sudden detriment of left ventricular and coronary flow. The risk of paradoxical embolism seems to be hardly greater than when the foramen ovale is patent in a normal heart (unless there is a septal aneurysm). Most patients with uncorrected atrial septal defect do not develop supraventricular arrhythmias until they are past childbearing age, and only a minority of women with acyanotic Ebstein's anomaly suffer from preexcitation tachycardias, although these may develop for the first time in pregnancy.

\section{Aortic stenosis}

Patients with left sided outflow tract obstruction may not tolerate a fall in systemic vascular resistance because of an inability to increase stroke volume, and tachycardia may cause ischaemia and failure. Women who are asymptomatic before pregnancy, have a healthy ECG, good left ventricular function, and who can achieve at least 7 mets on the treadmill without angina, a fall in blood pressure or ST segment depression will have no trouble. Doppler outflow velocity should increase during pregnancy if the left ventricle is coping. A fall in Doppler velocity or the development of tachycardia, dyspnoea or angina are danger signals. Hospital admission is indicated for rest and a $\beta$ blocker is needed to provide diastolic time for coronary flow and left ventricular filling. If possible the pregnancy should be kept going until the fetus is viable with delivery by caesarean section under general anaesthesia before dealing with the mother's valve. If relief is required earlier, balloon valvotomy may buy time ${ }^{12}$ but always with the risk of creating substantial regurgitation.

\section{Pulmonary hypertension and the Eisenmenger syndrome}

Pulmonary hypertension threatens a pregnant woman's life whether associated with a central shunt in the Eisenmenger syndrome or when solitary as after previous closure of a non-restrictive ventricular septal defect or arterial duct. The risk to the mother's life in the Eisenmenger complex (ventricular septal defect) remains close to $50 \%$ despite optimal management. Nothing has changed. ${ }^{34}$ (Sterilisation should be advised in all young women with the Eisenmenger syndrome. Laparoscopic sterilisation under general anaesthesia does not carry high risk. One of its many advantages over contraception is that, although it is like a bereavement, once it is over there 
is no room for second thoughts.) Patients who are first seen when pregnant should be told the risks and therapeutic abortion advised. If she decides to continue, the patient should be admitted as soon as resting saturation falls, but definitely before the end of the second trimester. The treatment is bed rest with prophylactic heparin, nasal oxygen, continuous pulse oximetry, and careful fetal monitoring. Rest will minimise right to left shunting and maximise fetal growth but, except in patients who manage to retain normal or near normal arterial saturation, fetal growth will eventually fail and the fetus has to be delivered. The safest route is by caesarean section under general anaesthesia with generous hydration, avoidance of systemic vasodilation agents, and prompt replacement of blood loss. On return to the intensive care unit after delivery, pulse oximetry and subcutaneous heparin are to be continued. Physiotherapy aids a programme of slow mobilisation. Sadly sudden death without warning occurs all too often and postmortem examination will reveal no cause. In monitored patients, systemic vasodilatation, bradycardia, and progressive right to left shunting precede cardiac arrest. In Eisenmenger complex either ventricle has free access to the pulmonary or systemic circulation. If systemic vascular resistance falls or pulmonary resistance rises the lung circulation is bypassed with fatal consequences. Patients with Eisenmenger ducts or atrial septal defect are only slightly more robust. ${ }^{5}$

In patients with pulmonary hypertension after ventricular septal defect closure, similar in-hospital care is given. Fetal growth is normal as the mother is acyanotic but the maternal risk is high. ${ }^{6}$ In a personal fully monitored case the pulmonary vascular resistance rose inexorably postpartum with progressive fall in systemic output, right ventricular failure, and death on the fifth postpartum day. Whether this could have been averted by earlier prostacyclin or nitric oxide therapy is uncertain.

\section{Volume loaded and poorly functioning ventricles}

Successful pregnancy is possible after the Fontan operation ${ }^{7}$ but tends to be uncomfortable because of increasing systemic venous pressure causing hepatic congestion and often distressing oedema of the lower extremities. The development of atrial flutter may jeopardise the fetus in patients with a right atrial-pulmonary artery conduit. Atrial thrombosis is a major threat in some Fontan patients and some may need continued anticoagulant treatment. Patients with atrial fenestrations are at risk from paradoxical embolism and may develop progressive cyanosis and consequent fetal growth retardation.

The integrity of ventricular function needs careful assessment after the Mustard or Senning operation for transposition as eventually the right ventricle, which handles the systemic circulation, will fail; however, a number of successful pregnancies have been reported. ${ }^{8}$ Failure of the morphological right but systemic left ventricle also tends to develop in patients with corrected transposition, and is often augmented by regurgitation through the left sided tricuspid valve. The development of atrial arrhythmias, particularly flutter, can be a major problem in these adult late postoperative patients.

\section{Potentially fragile aortas}

Women with the Marfan or Ehlers-Danlos syndromes face an increased risk of aortic dissection or rupture during pregnancy, as do some patients with coarctation of the aorta, even after previous correction.

Treatment with a $\beta$ blocker should continue throughout pregnancy. Women with Marfan syndrome whose aortic root is already dilated or who have a family history of aortic rupture should be advised to delay pregnancy until after aortic root replacement. Resuspension of the aortic valve is usually possible and avoids the need for long term anticoagulant treatment. ${ }^{9}$

\section{Prosthetic valves}

Both warfarin and heparin carry hazards during pregnancy; warfarin brings a small risk to the fetus while heparin compromises the mother. Warfarin treatment should not be interrupted during pregnancy in women with mechanical valves. ${ }^{111}$ Bioprostheses tend to deteriorate during pregnancy and will need early replacement at uncertain risk. There are as yet only anecdotal reports of pregnancy after the Ross procedure (pulmonary autograft in the aortic position and homograft in the pulmonary position).

\section{Cyanosis}

Cyanosed women with low pulmonary artery pressure usually survive pregnancy despite increased risks from paradoxical embolism. A falling arterial saturation should be countered by bed rest, and the tendency to thrombosis by subcutaneous heparin. Despite this, fetal growth is poor in proportion to the severity of desaturation (as was first shown in the late Helen Taussig's shunted Fallots ${ }^{12}$ ). In patients with pulmonary atresia and large aorta-pulmonary collaterals described in this issue of the fournal, pregnancy was associated with a predictably high rate of miscarriage, prematurity, and small for date babies. ${ }^{13}$ Fetal growth was normal after radical correction as it is after correction of tetralogy of Fallot. ${ }^{14}$

Normal delivery has been favoured for women with heart disease but good arguments can be made for more frequent use of caesarean delivery for some patients. In cyanosed women the effort of normal delivery causes increased right to left shunting and fetal hypoxemia; caesarean section gives premature babies their best chance of survival. It safeguards mothers with little circulatory reserve by eliminating maternal physical effort and expediting the birth process. Caesarean delivery under epidural anaesthesia minimises aortic wall stress in women with the Marfan syndrome and may be considered in a minority of patients with coarctation of the aorta who are considered vulnerable. Prophylactic antibiotics are discretionary but should be given to patients considered to be at especially high risk. These are patients with artificial valves or with a past history of endocarditis.

In general, if pregnancy is ever to be attempted it should not be delayed because unless a surgical procedure is planned the heart disease can only get worse and the risks will increase. The child's risk of congenital heart disease should be discussed and the advice of a clinical geneticist may be needed.

Optimal management of pregnancy in women with congenital heart disease is a team effort and such patients are best seen in joint antenatal cardiac clinics which offer continuity of care, where progress can be monitored, and the delivery strategy planned with the anaesthetist who is an integral part of the team.

The risk of pregnancy and likelihood of a successful outcome needs to be worked out individually because there is no dataset and "evidence based" cardiology cannot be practised. Commonsense and haemodynamic principles have to be applied instead.

Emeritus Professor of Cardiology,

CELIA M OAKLEY

United Kingdom 
1 Banning AP, Pearson JF, Hall RJC. Role of balloon dilatation of the aortic valve in pregnant patients with severe aortic stenosis. Br Heart $\mathcal{F} 1993$ 70:544-5.

2 Presbitero $P$, Prever SB, Brusca $A$. Interventional cardiology in pregnancy. Eur Heart $₹$ 1996;17:182-8.

3 Morgan-Jones A, Howitt G. Eisenmenger syndrome in pregnancy. $B M \mathcal{f}$ $1965 ; \mathbf{i}: 1627$.

4 Avila WS, Grinberg M, Snitcowsky R, Faccioli R, LaLuz PL, Bellotti G, et al. Maternal and fetal outcome in pregnant women with Eisenmenger's syndrome. Eur Heart 7 1995;16:460-4.

5 Gleicher N, Midwall J, Hochberger D, Jaffin H. Eisenmenger's syndrome and pregnancy. Obstet Gynecol Surv 1975;34:721-41.

6 Jackson GM, Dildy GA, Varner MW, Clark SL. Severe pulmonary hypertension in pregnancy following successful repair of ventricular septal defect in childhood. Obstet Gynecol 1993;82(Suppl):680-2

7 Cannobio M, Mair D. Pregnancy outcome following Fontan operation. Circulation 1993;88:1-290.

8 Clarkson PM, Wilson NJ, Neutze JM, North RA, Calder AL, Barratt-
Boyes BG. Outcome of pregnancy after the Mustard operation for transposition of the oreat arteries with intact ventricular septum. $7 \mathrm{Am}$ Coll position of the great arte

9 Child A. Management of pregnancy in Marfan syndrome, Ehlers-Danlos syndrome and the other heritable connective tissue diseases. In: Oakley $\mathrm{C}$, ed. Heart disease in pregnancy. London: BMJ Publishing Group, 1997:153-62.

10 Gohlke-Barwolf C, Acar J, Oakley C, Butchard E, Burckhardt D, Bordnor E, et al. Guidelines for prevention of thromboembolic events in valvular heart disease. Eur Heart $₹$ 1995; 16:1320-30.

11 Working Group of the British Cardiac Society and the Research Unit of the Royal College of Physicians Valvular Heart Disease. Investigation and management. London: RCP Publications, 1996.

12 Neill CA, Swanson S. Outcome of pregnancy in congenital heart disease [abstract]. Circulation 1961;24:1003.

13 Neumayer U, Somerville J. Outcome of pregnancies in patients with complex pulmonary atresia. Heart 1997;78:16-21.

14 Singh H, Bolton PJ, Oakley CM. Pregnancy after surgical correction of tetralogy of Fallot. $B M \Im$ 1982;285:168-70. 
vascular disease, risk factors, interventions, and prognosis, fulfilling criteria for a suitable non-invasive assessment of endothelial function. Furthermore, several groups have targeted this molecule as a means of intervening in the thrombotic process. ${ }^{16}$ The next five years will tell if this approach is successful.

The non-invasive approach outlined by Mullen and colleagues has provided invaluable opportunities to dissect the pharmacology of the endothelium. However, by its very nature such an approach is unlikely to provide epidemiological data or even data to compare groups with large numbers of subjects. We submit that plasma markers such as von Willebrand factor and soluble thrombomodulin are likely candidates for providing data of this nature.

ANDREW BLANN GREGORY LIP

Haemostasis, Thrombosis and Vascular Biology Unit, University Department of Medicine The City Hospital, Dudley Road, Birmingham B18 $7 Q H$, UK

1 Mullen MJ, Thorne SA, Deanfield JE, Jones $\mathrm{CJH}$. Non-invasive assessment of endothelial function. Heart 1997;77:297-8.

2 Lip GYH, Blann AD. Von Willebrand factor and its relevance to cardiovascular disease. Br Heart $\mathcal{f} 1995 ; 74: 580-3$.

3 Blann AD, Taberner DA. A reliable marker of endothelial cell dysfunction: does it exist? $\mathrm{Br}$ f Haematol 1995;90:244-8.

4 Badimon L, Badimon JJ, Chesebro JH, Fuster V. von Willebrand factor and cardiovascula disease. Thromb Haemostas 1993;70:111-18.

5 Greaves M, Pickering C, Knight G, Boulton ALM, Ball J, Ward JD, et al. Changes in the factor VIII complex in diabetic ketoacidosis: evidence of endothelial cell damage? Diabetologia 1987;30:160-5.

6 Van den Berg M, Boers GHJ, Franken DG Blom HJ, van Kamp GJ, Jakobs C, et al. Hyperhomocysteinaemia and endothelial dysfunction in young patients with peripheral arterial occlusive disease. Eur $₹$ Clin Invest 1995;25:176-81.

7 Thompson SG, Kienast J, Pyke SDM, Haverkate F. Hemostatic factors and the risk of myocardial infarction or sudden death in patients with angina pectoris. $N$ Engl $\mathcal{F}$ Med patients with angina

8 Blann AD, Miller JP, McCollum CN. Von Willebrand factor and soluble E-selectin in the prediction of cardiovascular disease progression in hyperlipidaemia. Atherosclerosis

9 Boffa MC. Considering cellular thrombomodulin distribution and its modulating factors can facilitate the use of plasma thrombomodulin as a reliable endothelial marker. modulin as a reliable endothelial masis 1996;26(Suppl 4):233-43.

10 Blann AD, Amiral J, McCollum CN. Circulating endothelial cell/leucocyte adhesion moleing endothelial cell/leucocyte adhesion molecules in ischaemic he

11 Seigneur M, Dufourcq P, Gin H, Delafaye C, Amiral J, Pruvost A, Boisseau MR. Plasma thrombomodulin levels increase with the severity of diabetic retinopathy. Blood Coag Fibrinolys 1994;5:845-6.

12 Blann AD, Amiral J, McCollum CN. Prognostic value of increased soluble thrombomodulin and increased E-selectin in ischaemic heart disease. Eur $\mathcal{f}$ Haem. [In press.]

13 Gearing AJH, Newman W. Circulating adhesion molecules in disease. Immunol Today 1993;14:506-12.

14 Blann AD, Seigneur M, Steiner M, Boisseau MR, McCollum CN. Circulating endothelial cell markers in peripheral vascular disease: cell markers in peripheral vascular disease: atherosclerotic disease. Eur $\mathcal{F}$ Clin Invest. [In press.]

15 Belch JJF, Shaw JW, Kirk G, McLaren M, Robb R, Maple C, Morse P. The white blood cell adhesion molecule E-selectin predicts restenosis in patients with intermittent claudication undergoing percutaneous transluminal angioplasty. Circulation 1997;95: 2027-31.

16 Ruggeri ZM. Inhibition of platelet vessel wall interaction. Platelet receptors, monoclonal antibodies, and synthetic peptides. Circulation 1990;81(Suppl 1):I35-9.

This letter was shown to the authors, who reply as follows.

We read with interest the letter from Drs Blann and Lip regarding the advantages and limitations of plasma markers of endothelial cell function. We share their interest in this area of research and its potential clinical application. We feel, however, that evaluation of nitric oxide mediated arterial physiology in large conduit arteries using the non-invasive techniques described ${ }^{1}$ may provide insight into the pathophysiology of vascular disease, be an early marker of endothelial injury, and a means of evaluating interventions early in the natural history of atherogenesis.

The value of these measures in predicting disease development and outcome is not known and is central to current research efforts. Our published data, however, indicate that this technique can be used to study endothelial function in large groups of subjects from early in childhood, to provide epidemiological data, compare groups of subjects with risk factors, and demonstrate beneficial response to interventions. ${ }^{2-5}$

M J MULLEN M E DEANFIELD

Great Ormond Street Hospital for Children NHS Trust, London WC1N $3 \mathcal{F H}$, UK

1 Celermajer DS, Sorensen KE, Gooch VM, Spiegelhalter DJ, Miller OI, Sullivan ID, $e$ al. Non-invasive detection of endothelial dysfunction in children and adults at risk of atherosclerosis. Lancet 1992;340:1111-15.

2 Leeson CPM, Whincup PH, Cook DG, Donald AE, Papacosta O, Lucas A, et al. Flow mediated dilatation in 9-11 year old children: the influence of intrauterine and childhood factors. Circulation. [In press.]

3 Celermajer DS, Sorensen KE, Bull C, Robinson J, Deanfield JE. Endotheliumdependent dilation in the systemic arteries of asymptomatic subjects relates to coronary asymptomatic subjects relates to coronary
risk factors and their interaction. $f \mathrm{Am} \mathrm{Coll}$ risk factors and their interac
Cardiol 1994;24:1468-74.

4 Sorensen KE, Celermajer DS, Georgakopoulos D, Hatcher G, Betteridge DJ, Deanfield JE. Impairment of endothelium-dependent dilation is an early event in children with familia hypercholesterolemia and is related to the lipoprotein (a) level. $\mathcal{f}$ Clin Invest 1994;93: 50-5.

5 Clarkson P, Adams MR, Powe AJ, Donald AE, McCredie R, Robinson J, et al. Oral L-arginine improves endothelium-dependent dilation in hypercholesterolemic young adults. $f$ Clin Invest 1996;97:1989-94.

\section{CORRECTION}

Pregnancy and congenital heart disease C M Oakley Heart 1997;78:12-14.

The first sentence of the section Atrial septal defects should have read:

"The only frailty of patients with unrepaired atrial septal defects is intolerance of blood loss that can force left to right shunting, to the sudden detriment of left ventricular and coronary flow."

And not as published. The error is regretted. 